\title{
On the FE Modeling of FRP-Retrofitted Beam-Column Subassemblies
}

\author{
H. R. Ronagh, and H. Baji ${ }^{*}$
}

(Received February 13, 2013, Accepted July 23, 2013)

\begin{abstract}
The use of fiber reinforced polymer (FRP) composites in strengthening reinforced concrete beam-column subassemblies has been scrutinised both experimentally and numerically in recent years. While a multitude of numerical models are available, and many match the experimental results reasonably well, there are not many studies that have looked at the efficiency of different finite elements in a comparative way in order to clearly identify the best practice when it comes to modelling FRP for strengthening. The present study aims at investigating this within the context of FRP retrofitted reinforced concrete beam-column subassemblies. Two programs are used side by side; ANSYS and VecTor2. Results of the finite element modeling using these two programs are compared with a recent experimental study. Different failure and yield criteria along with different element types are implemented and a useful technique, which can reduce the number of elements considerably, is successfully employed for modeling planar structures subjected to in-plane loading in ANSYS. Comparison of the results shows that there is good agreement between ANSYS and VecTor2 results in monotonic loading. However, unlike VecTor2 program, implicit version of ANSYS program is not able to properly model the cyclic behavior of the modeled subassemblies. The paper will be useful to those who wish to study FRP strengthening applications numerically as it provides an insight into the choice of the elements and the methods of modeling to achieve desired accuracy and numerical stability, a matter not so clearly explored in the past in any of the published literature.
\end{abstract}

Keywords: beam-column subassembly, FRP, concrete, retrofit, finite element analysis, ANSYS, VecTor2.

\section{Introduction}

The use of fibre reinforced polymer (FRP) composites in strengthening, reinforced concrete structures has risen considerably in recent years. Combining the strength of the fibers with the stability of the polymer resin, FRP offer ease of application lowered labour cost and extra durability. Researches originally and practicing engineers with about 10 years lag, have used FRP to strengthen different reinforced concrete members such as beams, columns and slabs. Extensive experimental studies have shown that externally bonded FRP can significantly increase the stiffness and load carrying capacity of the retrofitted structures. However, there have been reports of reduction in ductility associated with brittle behaviour due to bond failure and FRP rupture.

Experimental database for reinforced concrete structures retrofitted or strengthened using FRP sheets or fabric is extensive. In the context of beam-column subassembly, numerous studies have been carried out (El-Amoury 2004; Ghobarah and El-Amoury 2005; Karayannis and Sirkelis 2008; Pantelides et al. 2008; Alhaddad et al. 2012). In this

School of Civil Engineering, The University of Queensland, Brisbane, QLD 4072, Australia. *Corresponding Author; E-mail: h.baji@uq.edu.au Copyright $($ The Author(s) 2013. This article is published with open access at Springerlink.com area, different issues such as joint shear strengthening; increasing member stiffness and plastic hinge relocation have been investigated. Along with experimental studies, many researches have utilised finite element models to predict the behaviour of FRP strengthened beam-column subassemblies (Parvin and Granata 2000; Wong and Vecchio 2003; Mahini and Ronagh 2009; Alhaddad et al. 2012; Shrestha et al. 2013). Variety of finite element programs are currently available for the purpose of numerical study of FRP strengthened reinforced concrete structures. These programs can be divided into two categories: general-purpose commercial and purpose-made specialised programs. Amongst the commercial programs, ANSYS (2012) has been very popular Although commercial general-purpose programs such as ANSYS offer great flexibility and extensive element library, they suffer from many shortcomings when it comes to modelling specific features of certain type of structures like reinforced concrete structures (solid element is the only available element for modelling concrete, lack of appropriate material softening model for concrete, tension stiffening is based on simple model rather than fracture energy based models, lack of appropriate hysteretic rules for concrete material and rebar to concrete bond, absence of special modelling features needed in modelling concrete structures such as tension and compression softening, rebar dowel action and rebar buckling). In order to overcome these shortcomings, supplementary subroutine for special elements or material can be added to these programs 
by users. Examples of these subroutines can be found in the literature (Králik 2009). On the other hand, as a specialised program, VecTor2 (Wong and Vecchio 2003) is a powerful tool especially developed for nonlinear analysis of membrane concrete structures especially those with shear-critical behaviour (Vecchio and Bucci 1999).

This paper presents different modelling options available in ANSYS for modelling FRP retrofitted beam-column subassemblies. Various failure and yield criteria along with different element types will be investigated. Moreover, special features of the program VecTor2 (a specially developed software for analysis of reinforced concrete membrane structures) in modelling beam-column subassemblies is also discussed. Comparison will be made between the results of these program and the test results reported by Mahini (2005). This study aims to provide useful information in the context of FE modelling of FRP retrofitted reinforced concrete structures.

\section{Test Data}

For comparison purposes, references is made to the specimens tested by Mahini (2005) at the Structures Lab of the University of Queensland on five beam-column joints.
In his study, the scaled-down beam-column joints were retrofitted using web-bonded FRPs in order to relocate the plastic hinge away from the joint core. The specimens are taken from a 1/2.2 scaled reinforced concrete portal frame. The member section sizes and reinforcement that were obtained based on this scale, satisfied the limitation of the hydraulic actuator size and the ultimate capacity of the hydraulic jacks. Buckingham's theorem was used for scaling. Figure 1 shows the details of CFRP strengthened beamcolumn joint tested by Mahini (2005). For the purpose of comparison, five of his specimens are selected. Two of these are control specimens that are not strengthened with FRP, while the other three are strengthened with FRP. Reinforcement details are available in Mahini (2005).

Table 1 shows the FRP configuration, concrete properties and type of loading of the specimens used in Mahini (2005). The fibers are oriented along the beam. Thus, they provide stiffness only in the longitudinal direction of the beam and act as a unidirectional material. In the perpendicular direction, the saturant (a glue type material attaching the fibers to concrete) is only active. If the fiber and saturant are treated as one material, this material would be an orthotropic material, in which the properties in the two perpendicular directions are not the same. It is assumed that the fibers remain elastic up to the failure stress.

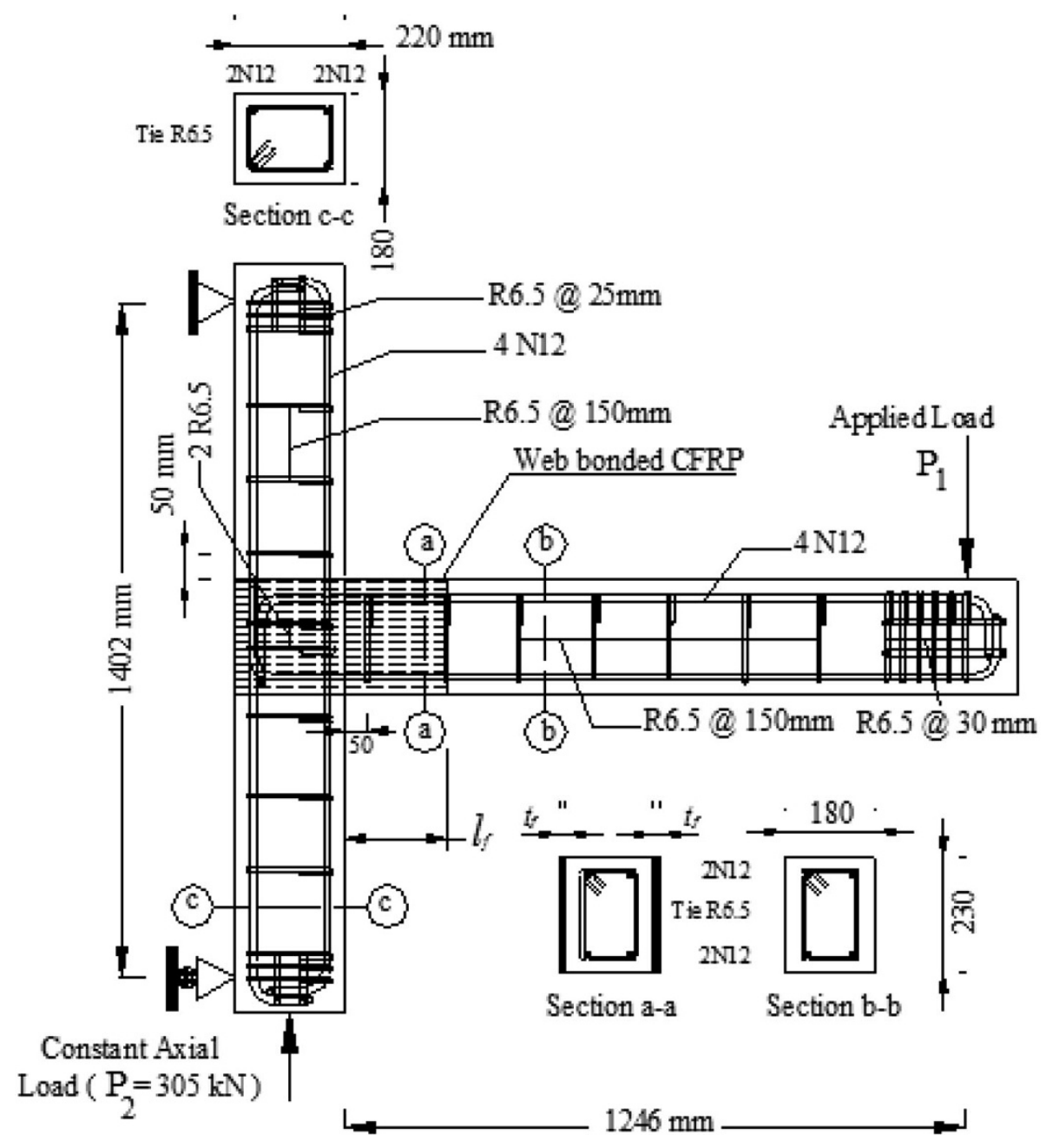

Fig. 1 Details of Mahini's (2005) specimens. 
Table 1 FRP configuration and concrete compressive strength (Mahini 2005).

\begin{tabular}{c|c|c|c|c|c|c|c}
\hline Specimen & No. of ply & $l_{f}(\mathrm{~mm})$ & $t_{f}(\mathrm{~mm})$ & $E(\mathrm{GPa})$ & $f_{u}(\mathrm{MPa})$ & $\varepsilon_{\text {rup }}$ & $f_{c}^{\prime}(\mathrm{MPA})$ \\
\hline \hline CSM0 & - & - & - & - & - & - & 40.82 \\
\hline RSM1 & 1 & 350 & 0.165 & 240 & 3,900 & 0.0155 & 40.82 \\
\hline RSM2 & 3 & 200 & 0.495 & 240 & 3,900 & 0.0155 & 47.17 \\
\hline CSC1 & - & - & - & - & - & - & 41.94 \\
\hline RSC1 & 3 & 200 & 0.495 & 240 & 3,900 & 0.0155 & 41.94 \\
\hline
\end{tabular}

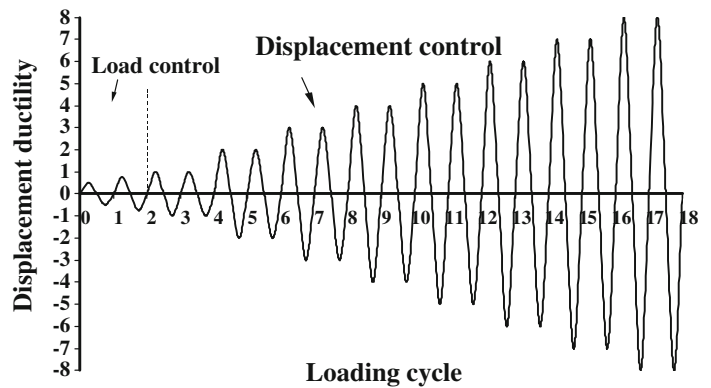

Fig. 2 Cyclic loading regime (Mahini 2005).

A constant axial force equal to $305 \mathrm{kN}$ was applied to the column. The beam tip was subjected to either monotonically or cyclically varying loads. Three of the specimens (CSM0, RSM1 and RSM2) were subjected to monotonic loading, while the other two (CSC1 and RSC1) were cyclically loaded. The cyclic loading regime is shown in Fig. 2. For the sake of simplicity, only the first four cycles were used in the numerical analysis of this study.

Two cycles are applied at each ductility ratio level from $\mu=\Delta / \Delta_{y}$ equal to 1 , going up to $2,3,4$ etc., where $\Delta$ is the beam-tip displacement and $\mu$ is the displacement ductility ratio. In this study, however, for the numerical analysis, only one cycle is applied at each ductility level. A displacementcontrol loading starting with the ductility ratio of one and ending with the ductility ratio of four is used.

\section{ANSYS Analytical Procedure}

ANSYS program has been used by many researchers for FE modeling of reinforced concrete structures. With regards to FRP strengthened reinforced concrete structures, Kachlakev et al. (2001) used ANSYS to examine the structural behavior of beams and bridges strengthened with FRP laminates. In their numerical modeling, SOLID65, LINK8 and SOLID46 elements were used to model concrete, bars and FRP laminates, respectively. Alhaddad et al. (2012) presented a detailed procedure for nonlinear finite-element analysis of FRP and textile reinforced mortar (TRM) upgraded reinforced concrete beam-column exterior joints using ANSYS. In their numerical modelling, they used similar elements to those used in Kachlakev et al. (2001). The FE results were compared with the test results through load-displacement behavior, ultimate loads, and crack pattern. Comparison of FE results with the experimentally observed response indicated that the proposed nonlinear FE model can accurately predict the behavior and response of tested RC beam-column joints. Parvin and Granata (2000) investigated the application of FRP laminates to exterior beam-column joints in order to increase their moment capacity using numerical analysis performed by ANSYS. In their study again SOLID65, LINK8 and SOLID46 elements were used to simulate the concrete, rebar and the FRP laminates, respectively. Mahini and Ronagh (2011) investigated the effectiveness of FRP strengthening in relocating the plastic hinge away from the face of the column in beamcolumn joints.

A quick literature review on finite element analysis of reinforced concrete structures strengthened by FRP laminates shows that the majority of researchers have used SOLID65, LINK8 and SOLID46 to model concrete, rebar and FRP. There are some exceptions though; Hawileh et al. (2012) recently used the ANSYS program to simulate reinforced concrete beams externally strengthened with shortlength CFRP plates. SOLID65 and LINK8 elements were used to model concrete and rebar. On the other hand, instead of using SOILD46 to model the FRP laminates, they used SHELL99 element with orthotropic material properties. Mirmiran et al. (2000) developed a nonlinear finite element model for the analysis of FRP confined concrete. SOLID65 was used to model concrete while the FRP sheets were modelled by tension-only SHELL41 elements. Their model showed the same type of stress concentration around the edges of square sections as observed in the experiments. Furthermore, they concluded that the cyclic analysis of FRPconfined concrete confirmed capability of the model to effectively predict the cyclic response of FRP-confined concrete. There has not been any study that explores the suitability of the elements in a comparative way; and therefore, this is the target the current study is aiming for.

\subsection{Concrete}

In ANSYS, the only element that is suitable for modeling concrete is SOLID65. This element is used for 3D modeling of solids with or without rebar. The solid is capable of cracking in tension and crushing in compression. The element is defined by eight nodes having three degrees of freedom at each node: translations in $\mathrm{x}, \mathrm{y}$ and $\mathrm{z}$ directions. Figure 3 shows the geometry of element SOLID65. Up to three different rebar specifications can be defined as smeared reinforcement (uniformly distributed reinforcement defined as rebar percentage in each direction using rebar cross 


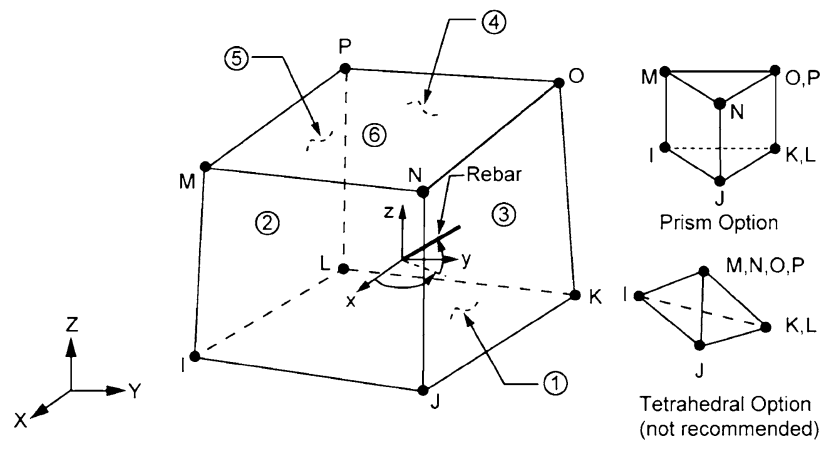

Fig. 3 Element SOILD65 geometry (ANSYS 2012).

section area and spacing). SOILD65 element is capable of plastic deformations as well as creep.

ANSYS uses William-Warnke (1974) failure criterion for assessing the state of failure. This failure surface function has five parameters. These parameters are used to find the tensile and compressive meridians. The five parameters that are required to define the William-Warnke failure surface are:

$f_{t} \quad$ Ultimate uniaxial tensile strength

$f_{c} \quad$ Ultimate uniaxial compressive strength

$f_{c b} \quad$ Ultimate biaxial compressive strength

$f_{1}$ Confined triaxial compressive strength (compressive meridian)

$f_{2} \quad$ Confined triaxial compressive strength (tensile meridian)

While the full five input parameters are needed to define the failure surface (as well as an ambient hydrostatic stress state on which parameters $f_{1}$ and $f_{2}$ are based), ANSYS can build the failure surface with a minimum of two constants that are the uniaxial tensile and compressive strengths. For the rest of the parameters, ANSYS uses default values taken from the William et al. (1974) study.

It should be noted that ANSYS treats William-Warnke function as a failure surface. Prior to failure, the behavior is elastic, and after cracking or crushing, the material completely fails at that point and the material stiffness suddenly drops to zero. In the case of having pure tension, ANSYS uses Rankin failure criteria for tension cut-off. Cracking is permitted in three orthogonal directions at each integration point. For the direction in which cracking occurs, tensile strength essentially becomes zero. When the crack closes, compressive stresses normal to the crack can be transferred. Material property for the directions in which crack has not occurred remains the same. Figure $4 \mathrm{a}$ shows the failure surface of concrete for the plane stress case. As is seen, for the tension stress state, ANSYS uses tension cut-off.

With regards to the concrete tension model, one of the shortcomings of ANSYS is that it does not use the concept of fracture energy which is widely used in the analytical models for concrete cracking. In ANSYS, cracking is defined by a single material property which is the tensile strength of concrete. To consider tension stiffening, stress relaxation has to be considered after cracking. Figure $4 \mathrm{~b}$ shows the model employed in ANSYS to consider tension stiffening. A constant $T_{c}$ is used to control the stiffening model which acts as a multiplier for the stress relaxation.

Shear behavior of SOLID65 element in ANSYS is controlled by two shear transfer coefficient for open and closed cracks. These coefficients represent conditions at the crack allowing for the possibility of shear sliding across the crack face. The value of these shear transfer coefficient ranges between zero and one, with zero representing a smooth crack (complete loss of shear transfer) and one (no loss of shear transfer).

Even though prior to failure (cracking or crushing), the behavior is assumed to be linear elastic, plasticity and/or creep may be combined with the concrete base properties to provide nonlinear behavior prior to failure. Usually, VonMises or Drucker-Prager (Drucker et al. 1952) plasticity is used for concrete. When a yield criterion is used in conjunction with the failure criteria, the yield surface must lay inside the concrete failure surface; otherwise, no yielding will occur. Drucker-Prager yield criterion is a modification of the Von-Mises criterion that accounts for the influence of the hydrostatic stress component; the higher is the hydrostatic stress (confinement pressure), the higher would be the yield strength. Equations 1 and 2 show the yield functions for Von-Mises and Drucker-Prager yield surfaces.

$$
\begin{aligned}
& \sqrt{J_{2}}-\sigma_{y}=0 \\
& \beta I_{1}+\sqrt{J_{2}}-\sigma_{y}=0
\end{aligned}
$$

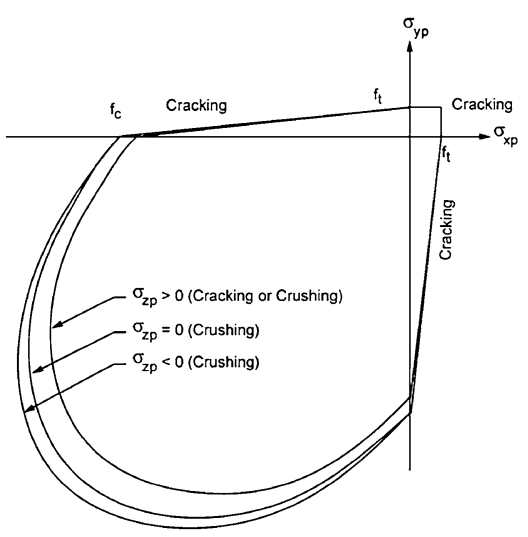

(a) Failure surface in biaxial stress state

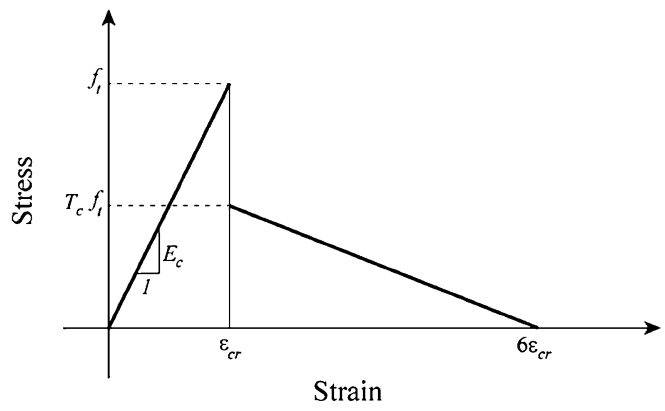

(b) Stress of cracked condition

Fig. 4 Failure surface in principal space with nearly biaxial stress (ANSYS 2012). 
where, parameters $\beta$ and $\sigma_{y}$ are the yield function parameters or material constants. Figure 5 shows both of the aforementioned yield criteria in the stress invariant plane. The Von-Mises function depends on only one stress invariant and does not include the effect of hydrostatic stresses, while Drucker-Prager includes the effect of hydrostatic stresses by adding another stress invariant.

Since the Drucker-Prager yield surface is a smooth version of the Mohr-Columb yield surface, it is often expressed in terms of the cohesion $c$ and the angle of internal friction $\phi$ that are used to describe the Mohr-Columb yield surface. If it is assumed that the Drucker-Prager yield surface inscribes the Mohr-Columb yield surface, then the expressions for finding parameters $\beta$ and $\sigma_{y}$ will be as follows.

$$
\begin{gathered}
\beta=\frac{2 \sin \phi}{\sqrt{3}(3-\sin \phi)} \\
\sigma_{y}=\frac{6(c) \cos \phi}{\sqrt{3}(3-\sin \phi)}
\end{gathered}
$$

where in Eqs. 3 and 4, $\phi$ is the angle of internal friction and $c$ is the cohesion value. The cohesion and the angle of internal friction for concrete are related to the concrete strength as shown in Eqs. 5 and 6.

$$
\begin{aligned}
& f_{c 0}=\frac{2(c) \cos \phi}{3-\sin \phi} \\
& k_{1}=\frac{1+\sin \phi}{1-\sin \phi}
\end{aligned}
$$

where variable $f_{c 0}^{\prime}$ is the unconfined strength of concrete and the parameter $k_{1}$ is the confinement effectiveness factor. Confinement effectiveness factor was first suggested as 4.1 by Richart (1929). It results in a friction angle of about $37^{\circ}$. Others have suggested different expressions for calculating this factor. Rochette (1996) suggested a direct approach to calculate $c$ and $\phi$ as given by Eqs. 7 and 8 .

$$
\begin{aligned}
& \phi=\sin ^{-1}\left[\frac{3}{1+1.592332 f_{c 0}^{\prime}(k s i)}\right] \\
& c(p s i)=\left(f_{c 0}^{\prime}(p s i)-1256\right) \frac{3-\sin \phi}{6 \cos \phi}
\end{aligned}
$$

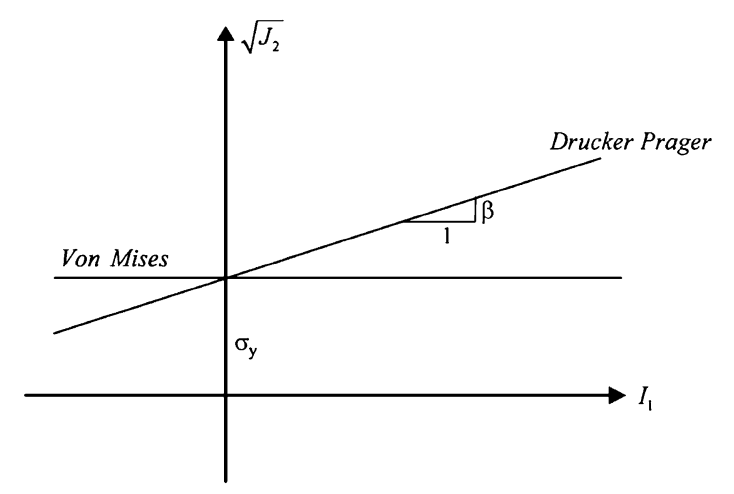

Fig. 5 Drucker-Prager and Von-Mises yield criteria.
The internal friction angle and cohesion shown in Eqs. 8 and 9 were used by other researchers (Mirmiran et al. 2000; Shahawy et al. 2000).

In order to simulate the nonlinear behavior of concrete, Von-Mises yield criterion could be used instead of DruckerPrager. Equation 9 shows the parabolic function of Hognestad stress-strain curve. Post-peak behavior of concrete involves strain softening. Several softening models are available for concrete. However, in the implicit version of ANSYS, softening of material could not be considered. In this study, the softening branch of stress-strain curve is replaced by a plateau.

$$
f_{c}=f_{c}^{\prime}\left[\frac{2 \varepsilon_{c}}{0.002}-\left(\frac{\varepsilon_{c}}{0.002}\right)^{2}\right]
$$

\subsection{Steel Rebar}

There are two options to model the reinforcement bars in ANSYS; smeared and discrete. When the smeared option is used, reinforcement is defined as a part of SOLID65 concrete element. Up to three directions could be used to define the smeared bars. Figure 3 shows the arrangement of reinforcing bars in the element. The smeared rebar is capable of tension and compression, but not shear. In each direction, smeared bars behave similar to a uniaxial material. The second option for modeling the reinforcing bars is to model them as a discrete element which is attached to the concrete elements. If discrete reinforcements are to be modeled, use of LINK and COMBIN elements in ANSYS is suggested; amongst which 2-node uniaxial tension-compression LINK8 element is the most common. As previously mentioned, Von-Mises yield criterion is generally used for metals such as steel. Steel can be modeled as a bilinear or a multilinear material. For cyclic analysis, generally one of the more common Kinematic hardening laws is used for the rebar. In the current study, bilinear Kinematic material behavior is used for bars. Longitudinal bars of beams and columns are modeled using discrete LINK8 element, but the shear bars (stirrup) are modeled using smeared reinforcement. Because no bond slip was reported in the Mahini's (2005) experimental study in the current research bond elements are not modeled.

\subsection{Fiber Reinforced Polymer (FRP)}

FRP composites are anisotropic; that is, their properties are different in different directions. A schematic of FRP composites is shown in Fig. 6. As is seen, the unidirectional lamina has three orthogonal planes of material properties (i.e., $x-y, x-z$, and $y-z$ planes). The xyz coordinate axes are referred to as the principal material coordinates, where the $x$ direction is the same as the fiber direction, and the $\mathrm{y}$ and $\mathrm{z}$ directions are perpendicular to the $\mathrm{x}$ direction.

As was explained in the previous sections, SOLID46 with anisotropic material properties has been used to model FRP laminates (Parvin and Granata 2000; Kachlakev et al. 2001; Mahini 2005). Tension-only membrane SELL41 and elastic 

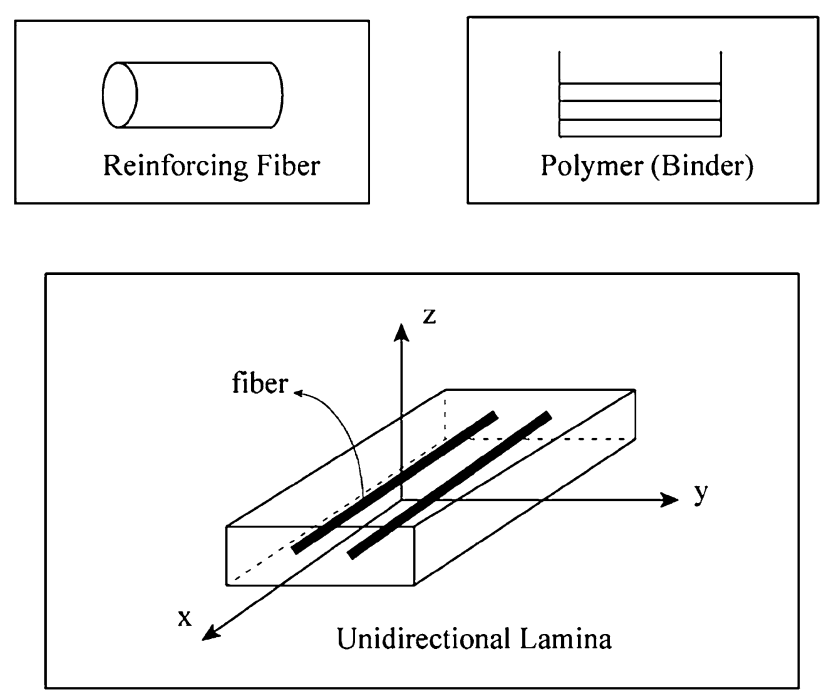

Fig. 6 Schematic of FRP composites (Kachlakev et al. 2001).

SHELL99 have also been used for this purpose (Mirmiran et al. 2000; Hawileh et al. 2012). One possibility to better model FRP in ANSYS which is not tried previously by researchers (although used for modeling reinforcing bars in concrete, (Hunley and Harik 2012)) is to use its reinforced shells and solids elements. These elements constitute a base element that can be reinforced with additional elements. In the case of FRP, the saturant can be used as the base element while fibers are added as reinforcing elements. Figure 6 shows the saturant and the fibers as different element. Reinforcing elements can be defined as discrete or smeared, and they can act as tension-only, compression only or tension and compression elements. In fact, for FRP, the tensiononly fibers are used. Element SHELL181 can be used as the base element for FRP composite material. Then, it can be reinforced using REINF265 smeared element. Each layer of reinforcement behaves as a unidirectional material. All layers including the base element perform like a parallel system. Perfect bond is assumed amongst the layers. Each layer can have its own thickness (defined as fiber area and space), orientation and local axis coordinate system. This option seems to be most appropriate for modeling FRP sheets in ANSYS. Fibers are embedded inside the base saturant and can have different directions without affecting each other. Even though the fibers are modeled as tension-only elements, the saturant which represents the base element can be modeled as an elastic element with isotropic properties.

In this study, two options will be considered to model FRP; tension-only membrane SHELL41 element and membrane-only option of SHELL181 reinforced with REINF265.

\subsection{Geometry and Meshing}

For verification purposes, test subassemblies were modeled in ANSYS taking advantage of plane stress condition of loading. The beam-column subassembly was represented by one row of solid elements. The beam and column sections were scaled down to narrower dimension. Therefore, only one element represents width of the section. Use of one row of solid elements is equivalent to using shell elements with a

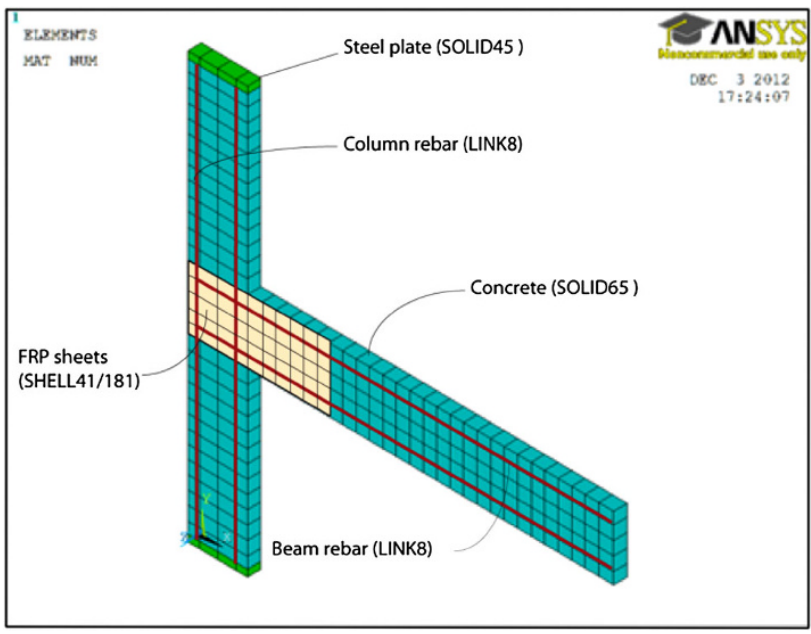

Fig. 7 Geometry, meshing and element type in ANSYS model.

thickness equal to the width of solid elements. Because ANSYS does not support reinforced concrete shell elements, the solid element is used to represent a condition that would behave similarly to the plane stress case. Width of the solid elements could be chosen arbitrarily. However, in order to have an element aspect ratio close to one, the width is set equal to the mesh size. In this method, the final results are independent of the solid element width. Figure 7 shows the meshed model. All used element types are shown in this figure.

As the beam and column cross section dimension is reduced, the steel rebar and FRP sheets thickness are proportionally reduced. Figure 8 shows how the column and beam cross sections are scaled down. The forces resulted from the analysis have to be scaled up after the analysis as a result, in order to represent forces in the structure. It is worth mentioning that in this kind of scaling, the stresses and deflections in the original and scaled structures remain similar.

Using this method for the finite element analysis considerably reduces the number of elements. Usually in experimental studies, planar loading is applied on specimens. Therefore, the method that is proposed here can be used for any analytical study. Using this method, considerable time is saved, and the designer can use a finer mesh for the planar structure. The attention can thus be shifted from analysing a complex system towards parametric studies on this simpler form and processing of the results.

\section{VecTor2 Analytical Procedure}

The second nonlinear finite element software explored in this study is VecTor2, a two dimensional nonlinear finite element analysis program for reinforced concrete structures developed at the University of Toronto. VecTor2 is based on the Modified Compression Field Theory (MCFT) by Vecchio and Collins (1986) and the Distributed Stress Field Model (DSFM) by Vecchio (2000). VecTor2 is capable of modeling two-dimensional reinforced concrete membrane 


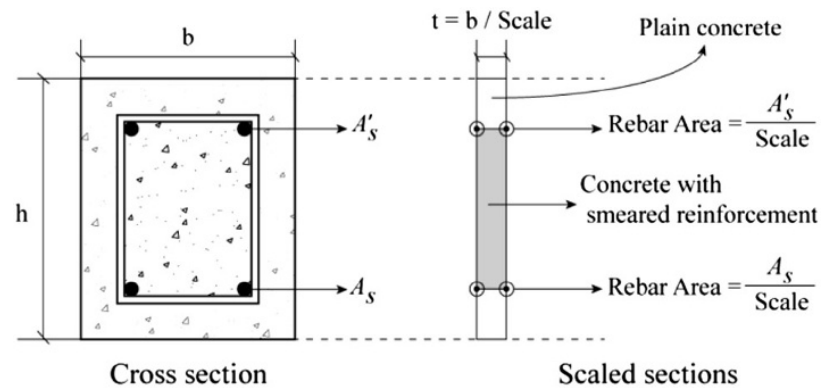

(a) Column section

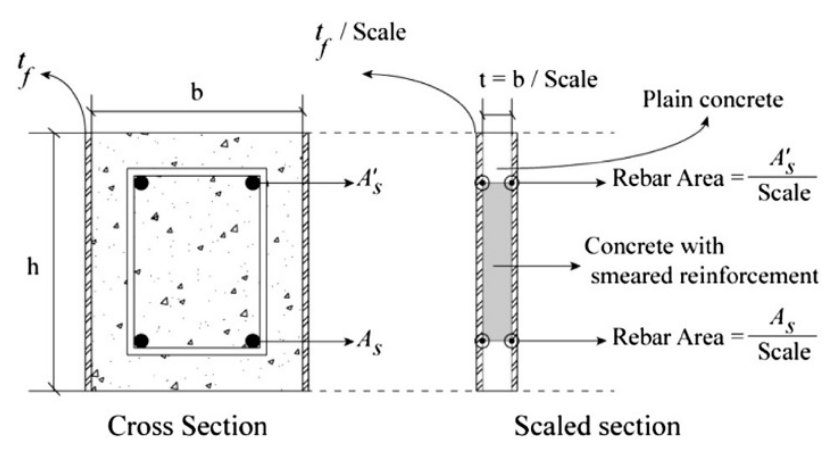

(b) Beam section

Fig. 8 Scaling technique for column and beam sections.

structures under monotonic, cyclic and reversed cyclic loading conditions. The element library of the program is limited. However, the element library covers many of the required elements for reinforced concrete structures. More importantly, it uses state-of-the-art material models for concrete, reinforcing and prestressing steel.

The MCFT is based on a smeared, rotating crack model for reinforced concrete, in which cracked concrete is represented as an orthotropic material with a unique constitutive relation. VecTor2 is a nonlinear finite element program that utilizes an incremental total load and iterative secant stiffness algorithm to produce an efficient and robust nonlinear solution. Additional information on VecTor2 program is given in "VecTor2 \& FormWorks User's Manual" by Wong (2002). Furthermore, the details of the constitutive models and their implementation into VecTor2 software have been described by Vecchio (2000).

VecTor2 program have been used in many studies. Vecchio and others undertook an analytical study on classic beam tests (Vecchio and Shim 2004), using VecTor2. They concluded that in a finite element simulation of the test beams, three dimensional stress effects were significant. They signified importance of the out-of-plane reinforcement in the accurate estimation of load-deformation behaviour of the test beams. Sagbas et al. (2011) have used the VecTor2 program to model beam-column subassemblies subjected to cyclic loading. They proposed general guidelines for effective finite element modelling of beam-column subassemblies. Bohl and Adebar (2011) used VecTor2 program to investigate the plastic hinge length in high-rise concrete shear walls. They reported that there is generally very good agreement between the predicted and observed curvature distributions. In the context of FRP repaired and strengthened structures, Vecchio and Bucci (1999) used VecTor2 program for the analysis of repaired reinforced concrete structures. They concluded that it is possible to implement modifications to nonlinear finite element procedures that will enable analysis of repaired, retrofitted or sequentially constructed concrete structures. Wong and Vecchio (2003) investigated modelling of reinforced concrete members with externally bonded FRP composites behaviour and especially bond between concrete and FRP materials using VecTor2 program. They showed that the implementation of link and contact elements, along with linear elastic and elastic-plastic bond laws produces accurate predictions of member response.

\subsection{Concrete}

VecTor2 uses three node constant strain triangular elements with six degrees of freedom and four-node plane stress rectangular elements with eight degrees of freedom to model concrete with distributed reinforcement. Plain as well as reinforced concrete with smeared reinforcement can be modeled using these elements. In VecTor2 program, various constitutive and behavioral models are available for concrete. The concrete model in VecTor 2 accounts for the reduction of compressive strength and stiffness due to transverse cracking and tensile straining. Concrete tension stiffening, crack shear slip, concrete tension splitting, concrete confinement and concrete dilatation can be considered in the analysis. Description of these effects is out of scope of this paper and details of all these options are available in VecTor2 user's manual (Wong and Vecchio 2003).

The concrete hysteretic response can be modeled with linear, nonlinear or nonlinear decay options. Typical tensile and compressive hysteretic responses of concrete material are shown in Fig. 9.

Palermo and Vecchio (2003) model with cyclic decay is assigned to concrete in order to model the hysteretic behavior of beam-column subassemblies in this study. Figure 9 shows the Palermo hysteretic behavior in tension and compression. Sagbas (2007) applied this model in the cyclic analysis of beam-column subassemblies.

\subsection{Steel Rebar}

Reinforcement can be modeled using either a smeared or a discrete representation. If bond-slip of reinforcement is to be considered, the use of discrete truss elements is unavoidable. On the other hand, when the longitudinal or transverse bars are sufficiently well distributed, smeared reinforcement is appropriate. Smeared reinforcement can be defined based on rebar percentage and rebar direction. The smeared reinforcement layer behaves as a unidirectional (in the specified direction) material. In order to model the discrete reinforcement, two-node truss bar element with four degrees of freedom is used.

The constitutive relationship used for reinforcing steel is based on a trilinear stress-strain behavior. The strain hardening effect of reinforcement until rupture is considered in VecTor2. Using the monotonic stress-strain curve as a backbone, the hysteretic response models define unloading 


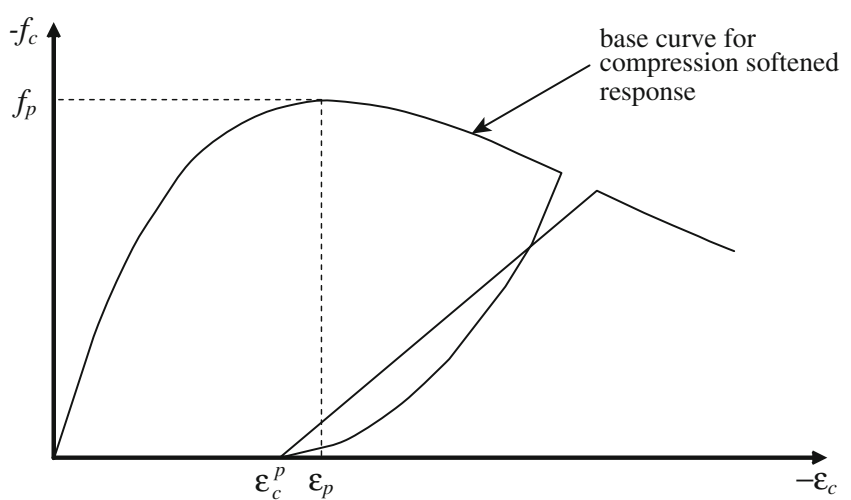

(a) Compression

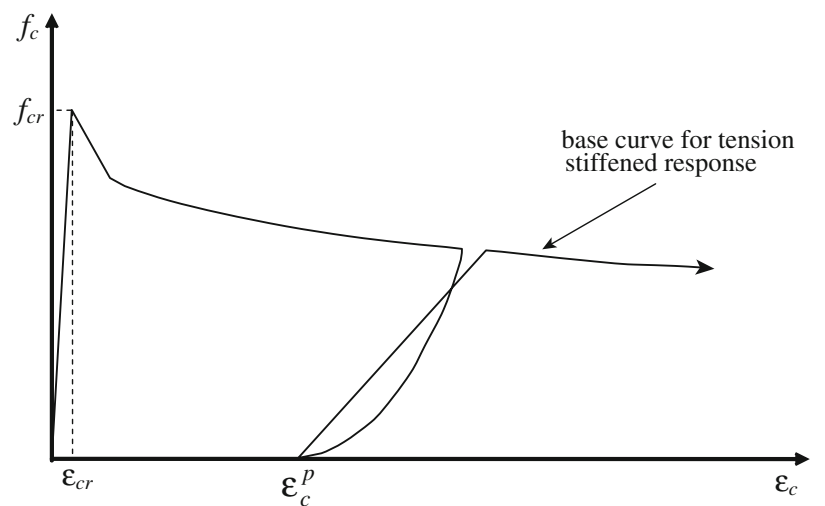

(b) Tension

Fig. 9 Palermo model of concrete hysteretic response

and reloading curves depending on the model selected from the VecTor2. By default, VecTor2 uses the model proposed by Seckin (1981) for the hysteretic response of reinforcement which includes the Bauschinger effect. Figure 10 illustrates the Seckin model that is used in VecTor2 program. In this model, after the plastic prestressing, the local stress changes upon load reversal resulting in premature yielding of reinforcement. The reloading curve is defined with a Ramsberg-Osgood formulation including the Bauschinger effect.

Dowel action as well as reinforcement buckling can be considered in the analytical model using VecTor2. In this study, transverse rebar (stirrups) are modeled based on smeared option, and all longitudinal reinforcement are modeled using truss elements. Although bond slip between concrete and rebar is modeled using link element, perfect bond has been assumed for this element. This means that no slip is considered between the bar truss elements and the concrete elements.

\subsection{Fiber Reinforced Polymer (FRP)}

Currently VecTor2 program does not have a specific element for modeling FRP materials. However, FRP fabric or sheets can be modeled using either smeared tension-only reinforcement layer or discrete tension-only truss elements. If the bond between FRP fabric and concrete is to be considered, only discrete truss elements can be used. FRP

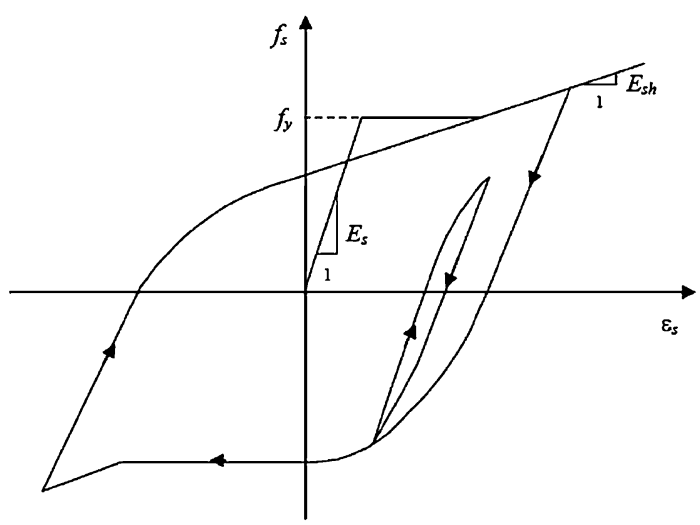

Fig. 10 Seckin model of reinforcement hysteretic response (Wong and Vecchio 2003). material is essentially elastic; i.e. prior to reaching the ultimate strength the material stress-strain relationship is linear and after that the material fails in a brittle manner. As the FRP material remains elastic, no special consideration needs to be given to the cyclic behavior. Essentially, loading and reloading follow the same path.

\subsection{Geometry and Meshing}

Due to the rectangular shape of the beam-column subassembly, only the rectangular concrete element is used for the finite element modeling of the subassembly. Because transverse reinforcements in different parts of beam and column are not the same, different concrete materials are assigned to these parts. Rectangular stirrups are replaced by smeared reinforcement in two perpendicular directions. These directions lie on the cross section of beam and column members. Figure 11 shows the divided regions of beam-column subassembly based on their material properties.

Longitudinal bars of the beam and the column are modelled using discrete truss element. Even though the link elements are defined between the nodes attached to the rectangular concrete element and the truss element, perfect bond is used in this study. Mild steel properties are used to model the two steel plates on the top and bottom of the column.

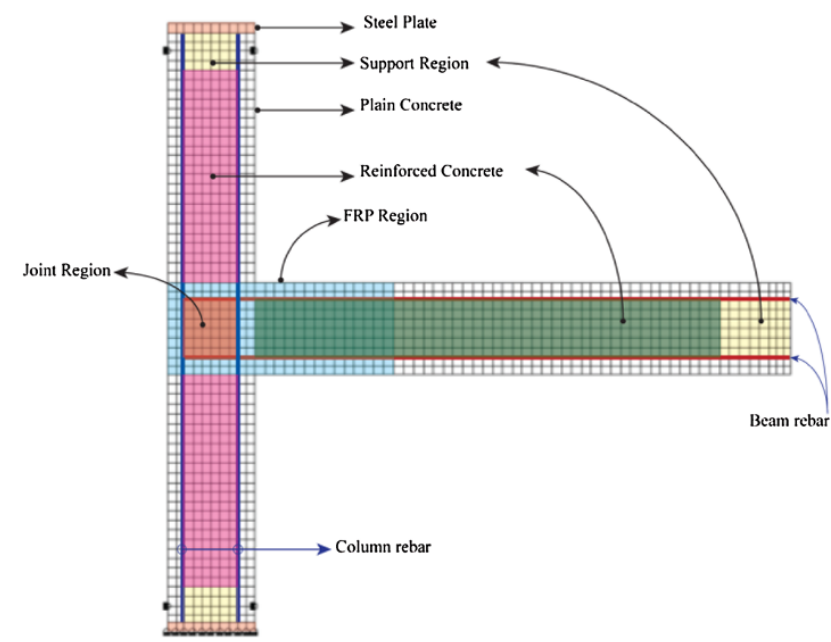

Fig. 11 Element mesh and different material regions in VecTor2. 
Table 2 Summary of ANSYS and VecTor2 features in modelling RC structures.

\begin{tabular}{|c|c|c|}
\hline Item & ANSYS & VecTor2 \\
\hline Concrete element & SOLID65 & Membrane ( 3 and 4 node) \\
\hline \multirow[t]{2}{*}{ Rebar element } & LINK8 & Truss \\
\hline & LINK10 & \\
\hline \multirow[t]{3}{*}{ FRP element } & SOLID46 & Tension only smeared rebar layer \\
\hline & SHELL41 & External FRP sheet layer \\
\hline & SHELL181 & \\
\hline \multirow[t]{2}{*}{ Bond element } & COMBIN39 & Link (2 node) \\
\hline & CONTACT & Interface (4 node) \\
\hline \multirow[t]{2}{*}{ Confinement model } & William-Wranke & Kupfer/Richard \\
\hline & Drucker-Prager & Montaya/Ottosen Selby \\
\hline Compression softening & Not included & Included \\
\hline Tension softening & Not included & Included \\
\hline Tension stiffening & Basic linear for convergence purposes & Based on fracture energy and variety of models \\
\hline \multirow[t]{4}{*}{ Concrete hysteretic rules } & Kinematic/isotropic & Linear w/no plastic offset \\
\hline & & Linear w/plastic offset \\
\hline & & Nonlinear w/plastic offset \\
\hline & & Palermo (w/decay) \\
\hline \multirow[t]{4}{*}{ Rebar hysteretic rules } & Kinematic/isotropic & Elastic-hardening (curvilinear) \\
\hline & & Elastic-hardening (trilinear) \\
\hline & & Elastic-plastic (bilinear) \\
\hline & & Bauschinger effect (seckin) \\
\hline Rebar dowel action & Not included & Included \\
\hline
\end{tabular}

Table 2 summarizes different features of the selected programs in simulating reinforced concrete structures. As is reflected in this table, VecTor2 program offers more extensive options in modelling reinforced concrete structures.

\section{Comparison of the Results}

In this section, using ANSYS and VecTor2 programs, the five specimens shown in Table 1 are analyzed. Three specimens are subjected to monotonic loading, while the other two are cyclically loaded. Displacement-control type loading is used in both programs. The maximum applied displacement is $80 \mathrm{~mm}$ for all specimens that are subjected to monotonic loading, and for those that are subjected to cyclic loading, four cycles are considered. First cycle starts with the yield displacement and in the following cycles, the displacement is two, three and four times the yield displacement.

Figure 12 shows the force-displacement curve for the specimen CSM0 based on different options available in ANSYS and VecTor2 programs. Specimen CSM0 is the control specimen and is not strengthened by FRP sheets.
Drucker-Prager and Von-Mises yield criteria as well as William-Warnke failure criterion are chosen in ANSYS. In addition, a case in which concrete behaves elastically is also considered. With regards to VecTor2, in one case, the prepeak stress-strain of concrete is defined based on the Hognestad model, while the post peak behavior is based on the modified Park-Kent model (VecTor2-softening curve in Fig. 12). For the second case, elastic behavior is considered for concrete (VecTor2-elastic curve in Fig. 12). In the third case, compressive behavior of concrete is similar to case 1 ; however, tension stiffening is used for concrete.

Figure 12 shows that the results of Drucker-Prager and Von-Mises yield criteria are almost identical. As expected assuming elastic behavior for concrete results in stiffer behavior. The model which is based on William-Warnke fails in properly predicting the specimen behavior, as it does not allow the concrete to take any load after crushing. Once one of the concrete solid elements fails, its stiffness drops to zero and as result the stiffness of the structure reduces. This type of failure would not normally occur in concrete structures as concrete experiences softening after reaching its peak stress. For other considered options, the crushing option is turned off in ANSYS. 


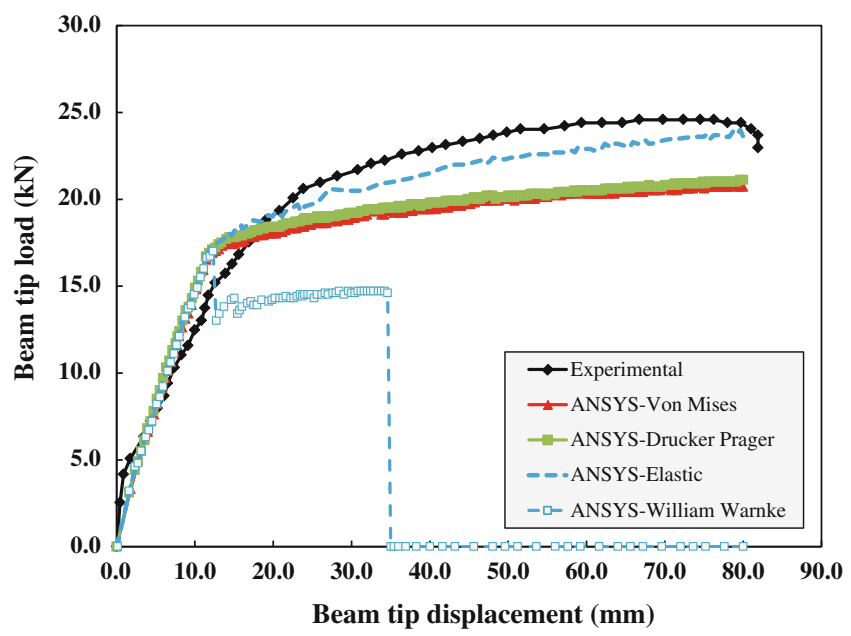

(a) ANSYS

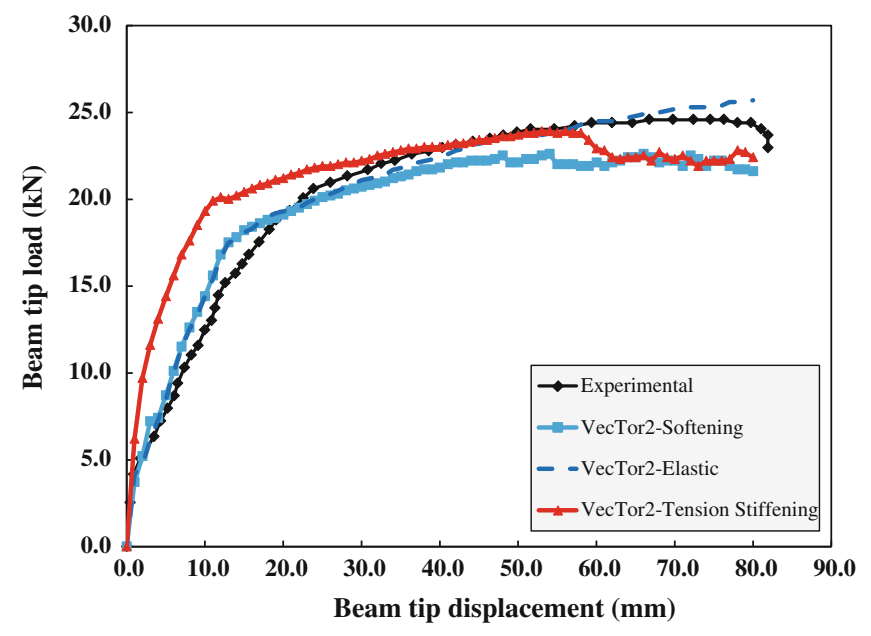

(b) VecTor2

Fig. 12 Comparison between load-displacement curves predicted by ANSYS and VecTor2 results for the specimen CSMO.

Table 3 Comparison of finite element and test results for monolithically loaded specimens.

\begin{tabular}{|c|c|c|c|c|c|c|c|c|c|}
\hline \multirow[t]{2}{*}{ Specimen } & \multicolumn{3}{|c|}{ Crack } & \multicolumn{3}{|c|}{ Yield } & \multicolumn{3}{|c|}{ Max } \\
\hline & Test & ANSYS & VecTor 2 & Test & ANSYS & VecTor2 & Test & ANSYS & VecTor2 \\
\hline \multicolumn{10}{|c|}{ 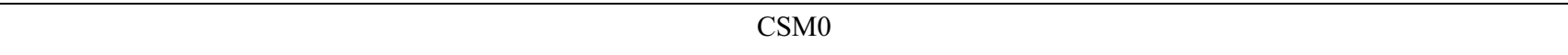 } \\
\hline $\mathrm{F}(\mathrm{kN})$ & 5.30 & 4.60 & 4.70 & 17.09 & 17.60 & 17.50 & 24.00 & 21.10 & 21.60 \\
\hline$\Delta(\mathrm{mm})$ & 1.70 & 2.30 & 2.00 & 14.00 & 13.30 & 13.00 & 80.00 & 80.00 & 80.00 \\
\hline \multicolumn{10}{|c|}{ RSM1 } \\
\hline $\mathrm{F}(\mathrm{kN})$ & 6.00 & 5.90 & 8.30 & 21.76 & 22.10 & 23.10 & 20.40 & 30.80 & 33.00 \\
\hline$\Delta(\mathrm{mm})$ & 2.10 & 2.80 & 3.00 & 19.97 & 16.00 & 17.00 & 80.00 & 80.00 & 80.00 \\
\hline \multicolumn{10}{|c|}{ RSM2 } \\
\hline $\mathrm{F}(\mathrm{kN})$ & 5.20 & 4.50 & 5.70 & 21.80 & 19.90 & 19.80 & 20.30 & 26.50 & 26.80 \\
\hline$\Delta(\mathrm{mm})$ & 1.50 & 1.40 & 2.00 & 18.80 & 13.40 & 13.00 & 80.00 & 80.00 & 80.00 \\
\hline
\end{tabular}

VecTor2 results are closer to the experimental curve. When tension stiffening is not considered in VecTor2, the results are closer to ANSYS and also to the experimental results. This shows that ANSYS does not have the appropriate tension stiffening model for concrete. One method for indirectly incorporating tension stiffening in the analysis of concrete structures is to modify the steel stress-strain curve (Ko et al. 2001). Nevertheless, when tension stiffening is not considered in VecTor2, results are closer to the experimental load-displacement curve. Thus, for all other considered specimens in VecTor2 analysis, the tension stiffening is not activated. Results in Fig. 12 show that assuming the elastic behavior for concrete material does not change the results considerably. This was expected, as for beam members the flexural behavior is dominant and the concrete strength has less contribution to the flexural strength. The steel yield strength or more broadly the steel stress-strain curve is the most important parameter. In Table 3 a comparison between the experimental and the finite element results for different states of loading are shown. As Table 3 shows, both programs well predict the crack and yield loads and displacements for specimen CSM0. However, they underestimate the maximum load capacity of the specimen. Possible inaccuracy in modeling the post yield behavior of steel rebar material could be one of the reasons for this underestimation.

As another comparative parameter, the distribution of curvature along the beam is calculated in both ANSYS and VecTor2. Using the resulting displacement at the nodes of the finite element model, the curvature at every section is indirectly calculated. Equation 10 shows how the curvature is calculated.

$$
\varphi=\frac{\varepsilon_{s}-\varepsilon_{c \max }}{d}
$$

In Eq. $10, \varepsilon_{s}$ and $\varepsilon_{c \max }$ are the strain in the tensile steel and the outermost concrete fiber respectively. The parameter $d$ is the effective depth of the cross section. Because the strain in concrete is negative, in Eq. 10 a negative sign is used for the concrete strain. By differentiating nodal displacements in adjacent nodes, the steel and concrete strains are calculated. Figure 13 illustrates the variation of curvature from the results of ANSYS and VecTor2. The curvature diagram shown in Fig. 13 is based on the final stage of loading which corresponds to $80 \mathrm{~mm}$ displacement. The agreement 


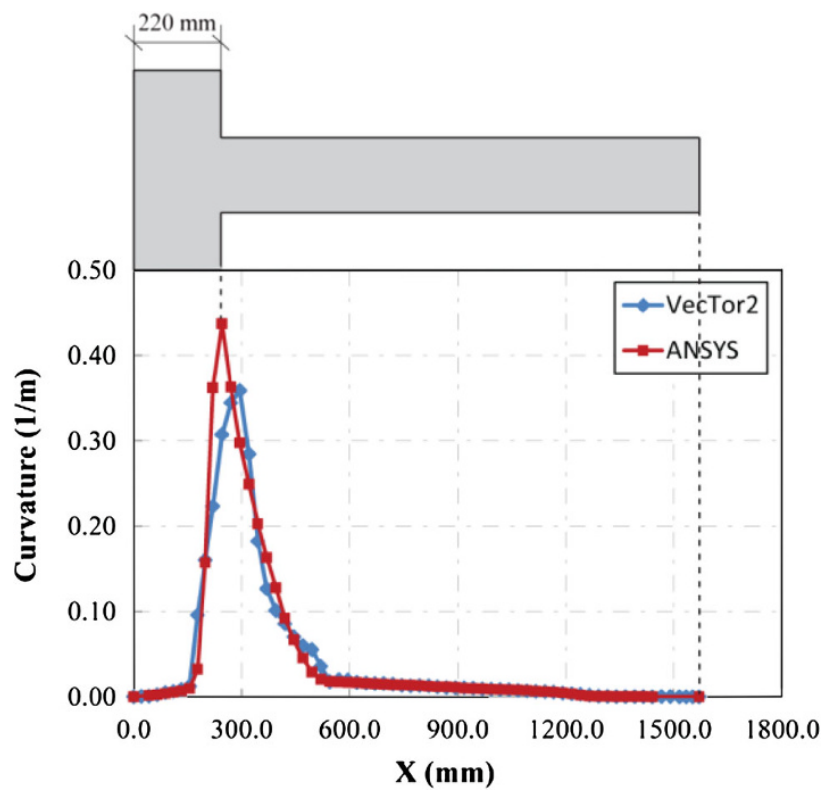

Fig. 13 Comparison between curvature diagrams predicted by ANSYS and VecTor2 for the specimen CSMO.

between two programs is quite reasonable. It should be noted that although the maximum mesh size used in the VecTor2 and ANSYS models is $25 \mathrm{~mm}$, the meshed models are not exactly identical. The points at which the curvature is calculated are the points shown in Fig. 13 and for the spaces in between the points, a linear variation is assumed.

Now, for the retrofitted specimens that are monotonically loaded, the results are discussed. Figure 14 shows the loaddisplacement curves for specimens RSM1 and RSM2 based on VecTor2 and ANSYS programs. For these specimens, the maximum mesh size is $25 \mathrm{~mm}$ and the specimens are loaded up to $80 \mathrm{~mm}$ at the beam tip. The specifications of these specimens are shown in Table 1. For comparison only, VonMises yield criterion along with tension cut-off is used in the ANSYS program. As previously discussed, Drucker-Prager yield criterion would result in the same results as Von-Mises criterion while the William-Warnke failure criterion is not appropriate as it takes away the crushed elements. VecTor2 model is based on the Hognestad curve for pre-peak and the modified Kent-Park model for the post-peak behavior. For comparison, results of using elements SHELL41 and reinforced SHELL181 are shown separately. The reinforcing element REINF265 which is based on smeared reinforcement layer is used to reinforce the SHELL181 element.

Results in Fig. 14 show that the agreement between VecTor2 and ANSYS results is reasonably good. Furthermore, SHELL41 and reinforced SHELL181 result in almost similar results for the force-displacement curve. For the retrofitted specimens, finite element results overestimate the load capacity of the both retrofitted specimens. According to Mahini's (2005) declaration, for RSM1 specimen and at the peak load, concrete crushing occurred at the face of the column, which was followed by the rupture of FRP. It was observed that the specimen exhibited a brittle failure mode constituting of concrete crushing, FRP buckling and debonding. In both specimens, concrete cover of the compression zone started to spall off at the peak load stage. In this study concrete spalling and FRP to concrete surface debonding were not modeled. Therefore, as expected the finite element results obtained from VecTor2 and ANSYS do not show any softening. VecTor2 results show small softening at the end of loading. However, this softening is a result of material softening not concrete spalling. There are several researchers that have modeled bond slip between FRP and concrete. Recently, Biscaia et al. (2013) have presented a load-displacement behavior model for bond-slip between FRP and concrete. Hawileh et al. (2012) utilized interface cohesion element for modeling debonding of FRP plates using ANSYS program. They concluded that the developed finite element models are capable of accurately predicting and capturing capacity the debonding failure mode of RC beams strengthened with FRP plates. Kim and Vecchio (2008) used a two-node link element in VecTor2 program for modeling FRP-retrofitted portal frame. Due to lack of adequate information, debonding between FRP and concrete was not modeled in this study. As shown in Fig. 14, VecTor2 exhibits a stiffer post-yield behavior in comparison with ANSYS. Furthermore, material softening which is considered in the VecTor2 model does not have a significant impact on the structural results.

The main failure indicators such as the ultimate strain of steel, concrete and CFRP sheets were not properly reported

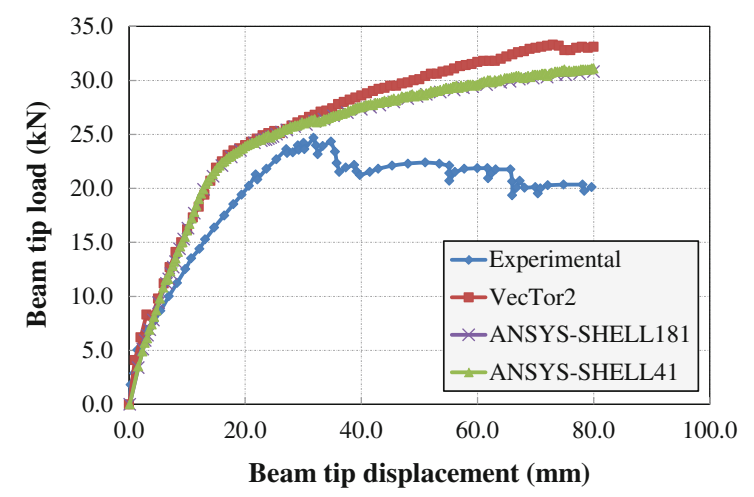

(c) RSM1 specimen

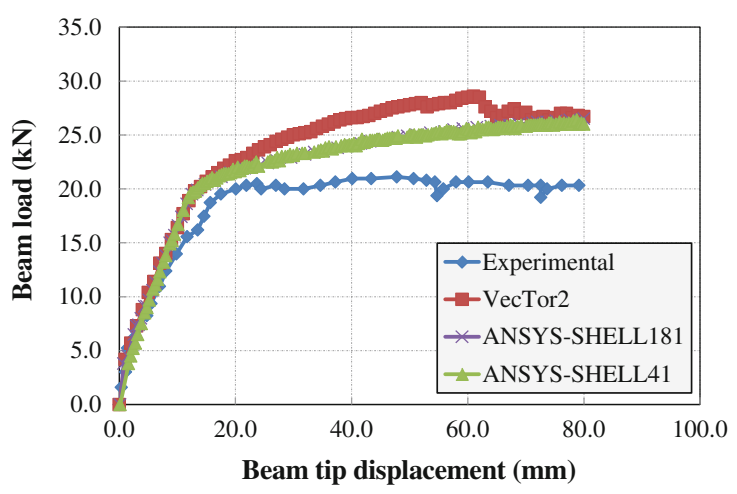

(d) RSM2 specimen

Fig. 14 Comparison between load-displacement curves predicted by ANSYS and VecTor2 results for the specimens RSM1 and RSM2. 
in the experimental program by Mahini. Therefore, in this research, values corresponding to $80 \mathrm{~mm}$ beam tip displacement are used as maximum load state. Table 3 shows that both programs well predict the load and displacement of the specimens at crack state. Although the yield load is well predicted, the yield displacement is underestimated by both programs. It is worth mentioning that in Mahini's experimental program, the mechanical properties of FRP sheets were not directly obtained in the laboratory and instead the information provided by the supplier was used. Mahini has reported some fibers rupture during test of retrofitted specimens. This was not observed in the finite element analysis. One likely reason could be that the supplier's ultimate stress for fibers does not represent the true average value. Furthermore, because of the inherent uncertainty in mechanical properties of material, the properties of tested material could be different from those used in the specimens. Therefore, in this study, the accuracy of results is limited by the accuracy of the available data.

Figure 15 shows the curvature diagram along the beam based on ANSYS and VecTor2 results. The curvature diagram corresponds to the final stage of loading ( $80 \mathrm{~mm}$ beam tip displacement). Results show that using either SHELL41 or SHELL181 would result in the same curvature distribution. VecTor2 curvature diagram is lower than those of ANSYS program. Load-displacement curves shown in Figs. 12 and 14 confirm that VecTor 2 results in higher post yield stiffness and accordingly lower deformations and curvature.

Mahini and Ronagh (2011) showed that FRP web bonding is an effective way in moving the plastic hinge away from the column face. The finite element results in this study confirm that view showing that the point of maximum curvature is slightly away from FRP cutting point. This means that the plastic hinge is moved away from the column face. In both ANSYS and VecTor2, the maximum stress in FRP fibers occurs at the column face. Table 4 shows the maximum FRP sheet stress obtained from these programs at the column face. The stress in ANSYS program is based on nodal stresses in the modeled shell elements, while in VecTor2 the stresses of smeared FRP layer are taken.

According to Table 4, when reinforced SHELL181 element is used, and in comparison with SHELL41 element option, lower stresses are resulted. This is partly is to the fact that in this case the saturant is modeled in addition to the fibers. A part of the applied load is taken by the saturant (modeled by SHELL181 element) which is used as a base for fibers (modeled by REINF265 element). Accepting the ultimate strength of $3900 \mathrm{MPa}$ for FRP, the resulted stresses show that the FRP material remains elastic. As previously discussed, the available mechanical properties of CFRP sheets were provided by the supplier and Mahini did not test the FRP sheets in the laboratory. If the true average mechanical properties of CFRP sheets were available, the finite element models would have been able to capture the progressive failure of the tested specimens.

For specimens CSC1 and RSC1, cyclic load is applied. Figure 16 shows the load-displacement results based on finite element modeling and the experiment. Four cycles are considered for the cyclic analysis. In the ANSYS model, Von-Mises yield criterion and tension cut-off are used for concrete material. Furthermore, steel rebar material is a kinematic hardening material. VecTor2 options for cyclic loading were discussed in the previous sections. In both finite element programs, FRP is modeled as a tension-only elastic material.

The results show that both programs are capable of capturing the load capacity of the test specimen in cyclic loading. However, VecTor2 results are closer to the experimental results. The hysteretic cycles obtained from ANSYS do not properly display the pinching effect which is common in response of reinforced concrete structures to cyclic loads. Pinching effect is a result of opening and closing of the cracks. On the other hand, VecTor2 results represent the pinching in the hysteretic cycles properly. Table 5 compares the experimental cyclic results and the finite element

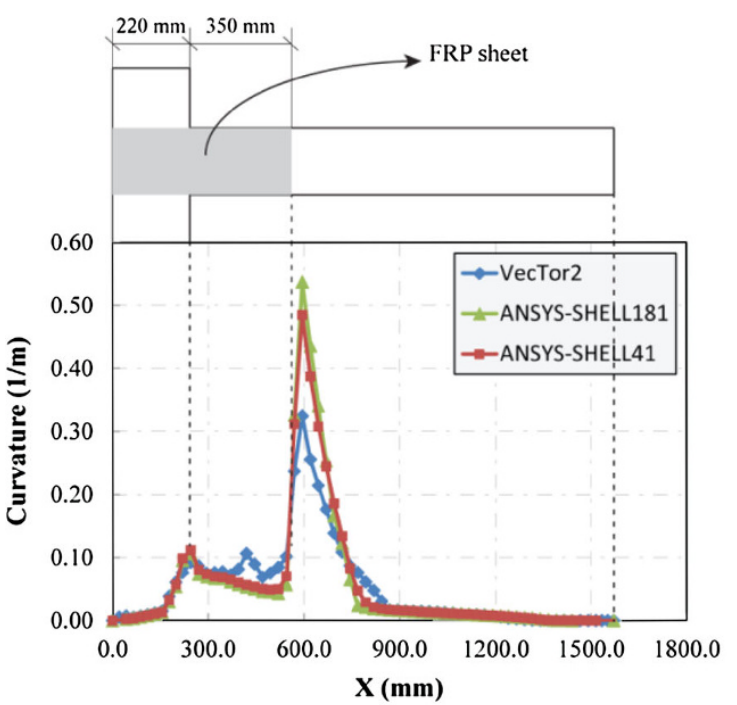

(e) RSM1 specimen

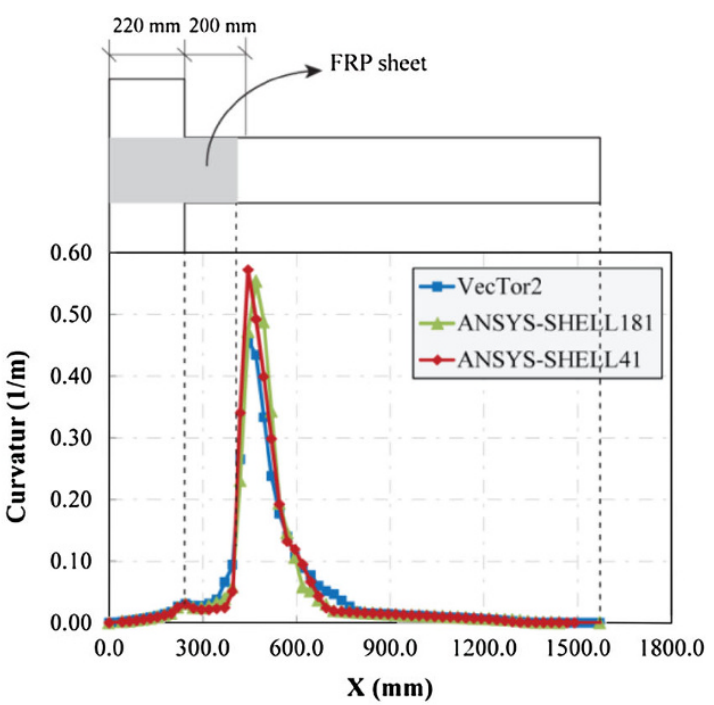

(f) RSM2 specimen

Fig. 15 Comparison between curvature diagrams predicted by ANSYS and VecTor2 for the specimens RSM1 and RSM2. 
Table 4 Maximum stress in FRP sheet (MPa).

\begin{tabular}{c|c|c|c}
\hline \multirow{2}{*}{ Specimen } & \multicolumn{2}{|c|}{ ANSYS } & VecTor2 \\
\cline { 2 - 4 } & SHELL181 & SHELL41 & 3,811 \\
\hline \hline RSM1 & 3,456 & 3,891 & 1,019 \\
\hline RSM2 & 1,047 & 1,154 & \\
\hline
\end{tabular}

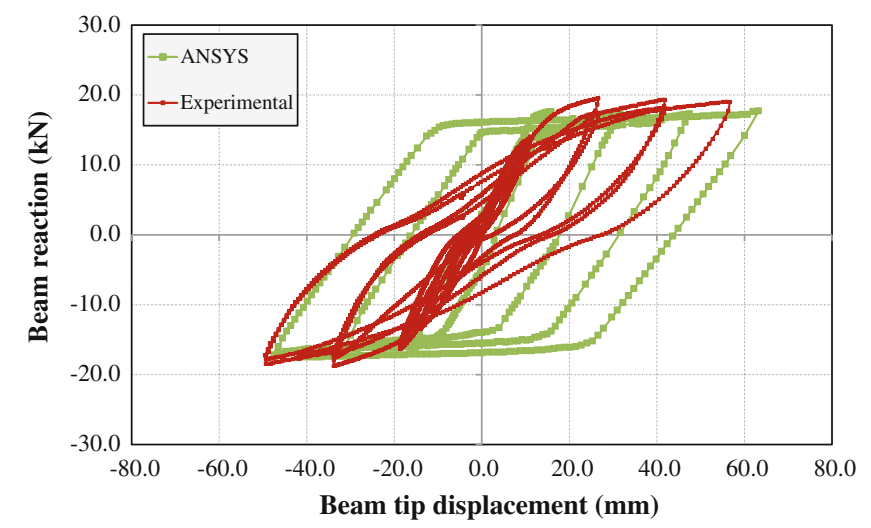

(a) $\operatorname{CSC1}$ (ANSYS-Experimental)

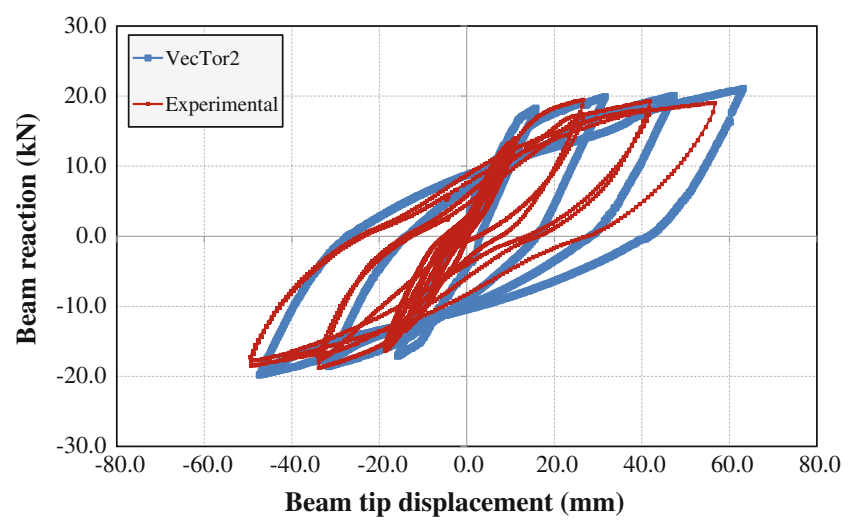

(c) $\operatorname{CsC1}$ (VecTor2-Experimental)

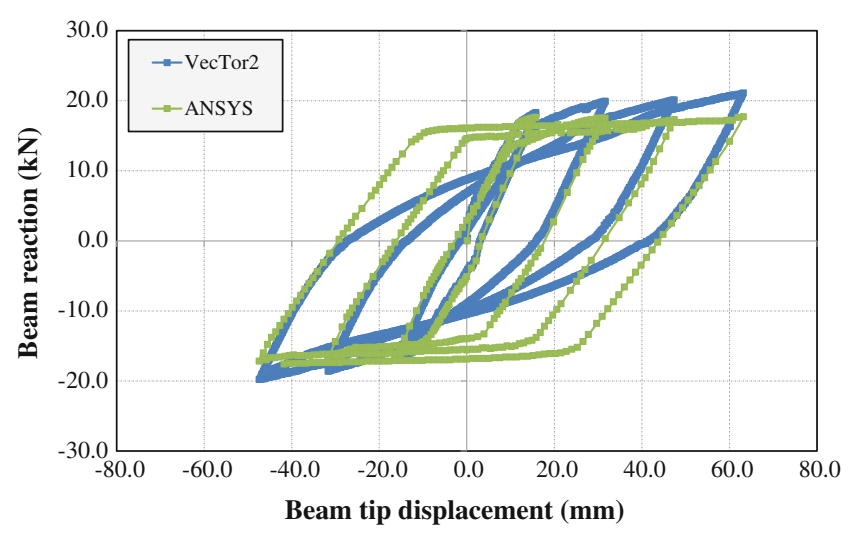

(e) CSC1(ANSYS-vecTor2)

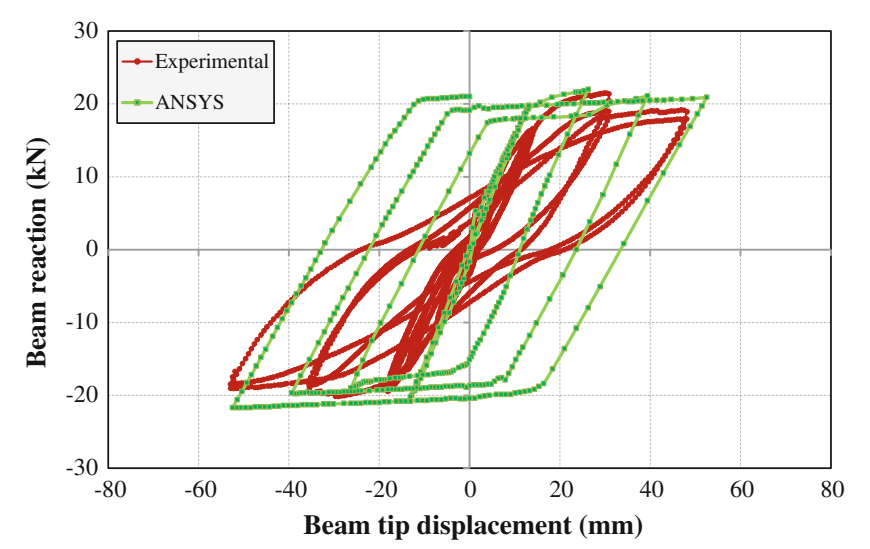

(b) RSC1 (ANSYS-Experimental)

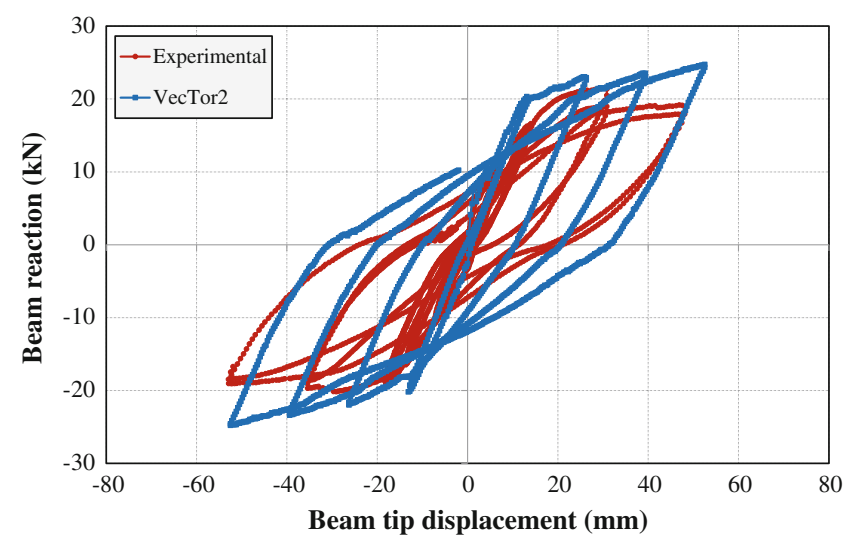

(d) $\mathrm{RSC} 1$ (VecTor2-Experimental)

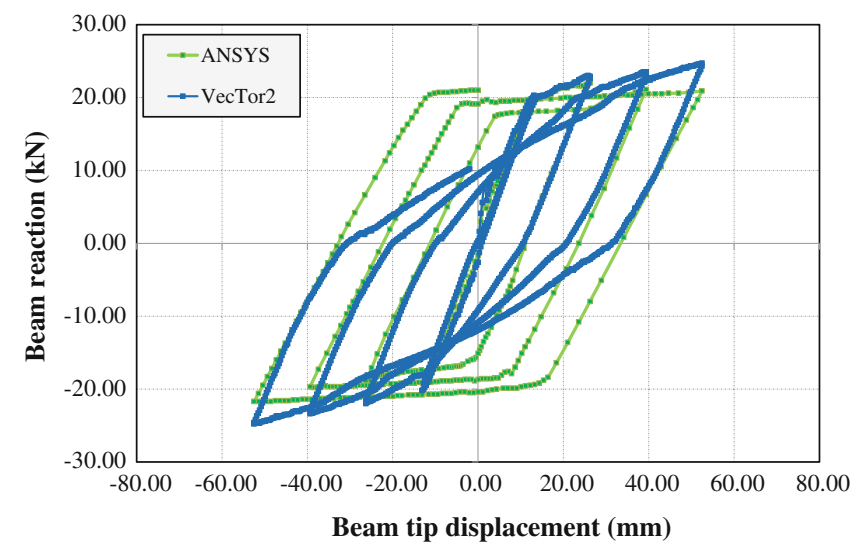

(f) RSC1(ANSYS-VecTor2)

Fig. 16 Comparison between load-displacement curves predicted by ANSYS and VecTor2 results for the specimens CSC1 and RSC1.

predictions for different loading cycles. As can be seen, the predicted load capacity obtained from both programs is in good agreement with the experimental results. The area enclosed in each hysteretic cycle is an indicator of dissipated energy. This measure is very important in evaluating seismic performance of structures. Because ANSYS response does not capture the pinching effect properly, the dissipate energy for each cycle of loading would be different from that of real 
Table 5 Comparison of finite element and test results for cyclically loaded specimens.

\begin{tabular}{|c|c|c|c|c|}
\hline & Cycles & & $\mathrm{CSC} 1$ & $\mathrm{RSC1}$ \\
\hline \multirow[t]{9}{*}{ Maximum load (kN) } & \multirow[t]{3}{*}{ Cycle 1} & Test & 15.77 & 19.00 \\
\hline & & VecTor2 & 16.60 & 19.50 \\
\hline & & ANSYS & 17.40 & 19.20 \\
\hline & \multirow[t]{3}{*}{ Cycle 2} & Test & 18.55 & 19.65 \\
\hline & & VecTor2 & 18.30 & 21.50 \\
\hline & & ANSYS & 17.50 & 21.60 \\
\hline & \multirow[t]{3}{*}{ Cycle 3} & Test & 18.42 & 19.08 \\
\hline & & VecTor2 & 19.50 & 22.10 \\
\hline & & ANSYS & 17.20 & 21.10 \\
\hline \multirow[t]{3}{*}{ Dissipated energy $(\mathrm{kN} \mathrm{mm})$} & \multirow[t]{3}{*}{ Cycle 3} & Test & 1,045 & 1,241 \\
\hline & & VecTor2 & 1,142 & 1,226 \\
\hline & & ANSYS & 1,881 & 1,649 \\
\hline
\end{tabular}

response. As can be seen in Table 5, by properly capturing the pinching effect, VecTor2 gives more accurate result for the dissipated energy.

VecTor2 is basically a special program developed for the analysis of reinforced concrete structures and hysteretic response is well addressed in this software. Although, ANSYS is capable of doing cyclic analysis, it does not have the appropriate rules for unloading and reloading of the reinforced concrete structures. To overcome this problem in ANSYS, special user-defined subroutines may be linked up in order to enhance its element library and material models.

\section{Conclusion}

From the finite element modeling and analysis of retrofitted beam-column subassemblies, the following conclusions can be drawn:

1. For planar reinforced concrete structures subjected to inplane loading, it is possible to model one row of solid elements in ANSYS. Accordingly, the rebar steel and the thickness of the FRP sheets are scaled down. This technique considerably reduces the number of elements and more attention could be paid to refining the mesh size.

2. As it does not consider the material softening properly, William-Warnke failure criteria in ANSYS cannot suitably predict the behavior of reinforced concrete structures. The crushed elements are removed from the model and that could lead to premature failure which is not consistent with the real behavior of reinforced concrete structures. Drucker-Prager yield criterion can be used as a proper yield criterion for concrete material.

3. In ANSYS, element SHELL41 and reinforced SHELL181 element (reinforced with REINF265 element) with tension-only and membrane options can model the FRP sheets properly. On the other hand, smeared tension-only layer of FRP sheet or rebar could be used for modeling FRP in VecTor2 program.

4. There is good agreement between ANSYS and VecTor2 results in monotonic loading. Finite element results can well predict crack and yield state displacements and forces. However, due to uncertainties in material properties such as post yield stiffness of steel rebar and FRP rupture strain, there is disparity between the finite element results and those of experimental results for post yield behavior.

5. Although ANSYS programs can predict the load capacity in cyclic loading, it is unable to properly model the pinching effect in cyclic loading of reinforced concrete structures properly. On the other hand, VecTor2 can well simulate the cyclic behavior of the modeled structures and consequently provide accurate estimation of dissipated energy during cyclic loading.

\section{Open Access}

This article is distributed under the terms of the Creative Commons Attribution License which permits any use, distribution, and reproduction in any medium, provided the original author(s) and the source are credited.

\section{References}

Alhaddad, M. S., Siddiqui, N. A., Abadel, A. A., Alsayed, S. H., \& Al-Salloum, Y. A. (2012). Numerical investigations on the seismic behavior of FRP and TRM Upgraded RC exterior beam-column joints. Journal of Composites for Construction, 16(3), 308-321.

ANSYS Manual. (2012). ANSYS Inc., Canonsburg, PA.

Biscaia, H. C., Chastre, C., \& Silva, M. A. (2013). Nonlinear numerical analysis of the debonding failure process of 
FRP-to-concrete interfaces. Composites Part B Engineering, 50, 210-223.

Bohl, A., \& Adebar, P. (2011). Plastic hinge lengths in high-rise concrete shear walls. ACI Structural Journal, 108(2), 148-157.

Drucker, D., Prager, W., \& Greenberg, H. (1952). Extended limit design theorems for continuous media. Quarterly of Applied Mathematics, 9(4), 381-389.

El-Amoury, T. A. (2004). Seismic rehabilitation of concrete frame beam-column joints. $\mathrm{PhD}$ Thesis, McMaster University, Ottawa, Canada, $351 \mathrm{pp}$.

Ghobarah, A., \& El-Amoury, T. (2005). Seismic rehabilitation of deficient exterior concrete frame joints. Journal of Composites for Construction, 9(5), 408-416.

Hawileh, R. A., Naser, M. Z., \& Abdalla, J. A. (2012). Finite element simulation of reinforced concrete beams externally strengthened with short-length CFRP plates. Composites Part B Engineering, 45(1), 1722-1730.

Hunley, C. T., \& Harik, I. E. (2012). Structural redundancy evaluation of steel tub girder bridges. Journal of Bridge Engineering, 17(3), 481-489.

Kachlakev, D., Miller, T., Yim, S., Chansawat, K., \& Potisuk, T. (2001). Finite element modeling of reinforced concrete structures strengthened with FRP laminates. Final Report SPR, 316, 2001.

Karayannis, C. G., \& Sirkelis, G. M. (2008). Strengthening and rehabilitation of RC beam-column joints using carbon-FRP jacketing and epoxy resin injection. Earthquake Engineering and Structural Dynamics, 37(5), 769-790.

Kim, S.-W., \& Vecchio, F. J. (2008). Modeling of shear-critical reinforced concrete structures repaired with fiber-reinforced polymer composites. Journal of Structural Engineering, 134(8), 1288-1299.

Ko, M.-Y., Kim, S.-W., \& Kim, J.-K. (2001). Experimental study on the plastic rotation capacity of reinforced high strength concrete beams. Materials and Structures, 34(5), $302-311$.

Králik, J. (2009). Seismic analysis of reinforced concrete frame-wall systems considering ductility effects in accordance to Eurocode. Engineering Structures, 31(12), $2865-2872$.

Mahini, S. S. (2005). Rehabilitation of exterior RC beam-column joints using web-bonded FRP sheets. $\mathrm{PhD}$ Thesis, School of Civil Engineering, The University of Queensland, Brisbane, Australia, 343 pp.

Mahini, S., \& Ronagh, H. (2009). Numerical modelling of FRP strengthened RC beam-column joints. Structural Engineering and Mechanics, 32(5), 649-665.

Mahini, S. S., \& Ronagh, H. R. (2011). Web-bonded FRPs for relocation of plastic hinges away from the column face in exterior RC joints. Composite Structures, 93(10), 2460-2472.

Mirmiran, A., Zagers, K., \& Yuan, W. (2000). Nonlinear finite element modeling of concrete confined by fiber composites. Finite Elements in Analysis and Design, 35(1), 79-96.

Palermo, D., \& Vecchio, F. J. (2003). Compression field modeling of reinforced concrete subjected to reversed loading: formulation. ACI Structural Journal, 100(5), 616-625.
Pantelides, C. P., Okahashi, Y., \& Reaveley, L. (2008). Seismic rehabilitation of reinforced concrete frame interior beamcolumn joints with FRP composites. Journal of Composites for Construction, 12(4), 435-445.

Parvin, A., \& Granata, P. (2000). Investigation on the effects of fiber composites at concrete joints. Composites Part B Engineering, 31(6), 499-509.

Richart, F. E., Brandtzæg, A., \& Brown, R. L. (1929). Failure of plain and spirally reinforced concrete in compression. Normal, IL: Illinois State University.

Rochette, P., \& Labossiere, P. (1996). A plasticity approach for concrete columns confined with composite materials. In Second International Conference on Advanced Composite Materials in Bridges and Structures, Montreal.

Sagbas, G. (2007). Nonlinear finite element analysis of beamcolumn subassemblies. Master of Applied Science, Department of Civil Engineering, University of Toronto, Toronto, Canada, $182 \mathrm{pp}$.

Sagbas, G., Vecchio, F., \& Christopoulos, C. (2011). Computational modeling of the seismic performance of beamcolumn subassemblies. Journal of Earthquake Engineering, 15(4), 640-663.

Seckin, M. (1981). Hysteretic behaviour of cast-in-place exterior beam-column-slab subassemblies. $\mathrm{PhD}$ thesis, Department of Civil Engineering, University of Toronto, Toronto, Canada, 1981, 266 pp.

Shahawy, M., Mirmiran, A., \& Beitelman, T. (2000). Tests and modeling of carbon-wrapped concrete columns. Composites Part B Engineering, 31(6), 471-480.

Shrestha, R., Smith, S. T., \& Samali, B. (2013). Finite element modelling of FRP-strengthened RC beam-column connections with ANSYS. Computers and Concrete: An International Journal, 11(1), 1-20.

Vecchio, F. (2000). Disturbed stress field model for reinforced concrete: Formulation. Journal of Structural Engineering, 126(9), 1070-1077.

Vecchio, F., \& Bucci, F. (1999). Analysis of repaired reinforced concrete structures. Journal of Structural Engineering, 125(6), 644-652.

Vecchio, F. J., \& Collins, M. P. (1986). The modified compression-field theory for reinforced concrete elements subjected to shear. ACI Journal, 83(2), 219-231.

Vecchio, F., \& Shim, W. (2004). Experimental and analytical reexamination of classic concrete beam tests. Journal of Structural Engineering, 130(3), 460-469.

William, K. J., \& Warnke, E. P. (1974). Constitutive model for the triaxial behaviour of concrete. In Proceedings of the International Assoc. for Bridge and Structural Engineering. Bergamo, Italy: ISMES Press.

Wong, P., \& Vecchio, F. (2002). VecTor2 and FormWorks user's manual. Toronto, Canada: University of Toronto.

Wong, R. S. Y., \& Vecchio, F. J. (2003). Towards modeling of reinforced concrete members with externally bonded fiberreinforced polymer composites. ACI Structural Journal, $100(1), 47-55$. 